\title{
Do CRA Agreements Influence Lending Patterns?
}

\author{
Raphael W. Bostic \\ Board of Governors of the Federal Reserve System \\ University of Southern California \\ bostic@usc.edu \\ Breck L. Robinson \\ University of Delaware \\ robinsob@be.udel.edu
}

July 2002

Please do not cite without permission from the authors. 


\title{
Do CRA Agreements Influence Lending Patterns?
}

\author{
Raphael W. Bostic and Breck L. Robinson
}

\begin{abstract}
$\underline{\text { Abstract }}$
Lenders have increasingly responded to regulatory and public pressures to provide credit to lower-income and minority communities by entering into CRA agreements, which typically involve pledges to extend a certain volume of lending to targeted groups and communities. This paper considers the broader impact of these CRA agreements by examining whether they are associated with changes in lending to lower-income and minority communities in the markets where they are initiated. Using a speciallyconstructed panel of counties that includes information on CRA agreements provided by the National Community Reinvestment Coalition, we find the number of newly-initiated CRA agreements in a county to be associated with significant increases in CRA, minority, and overall conventional mortgage lending in a county over a 3-year period. The results are consistent with the view that the increases in lending represent new lending, with some evidence suggesting the increases in lending are relatively short-lived. No comparable relationships are observed between CRA agreements and changes in government-backed lending. Overall, the results are consistent with the notion that lenders view CRA agreements as a form of insurance against the potentially large and unknown costs associated with fair lending violations, poor CRA performance ratings, and adverse publicity from CRA-related protests of mergers or other applications. The results are also consistent with the view that the effectiveness of CRA agreements in increasing lending activity is ultimately determined by the persistence and sophistication of community groups in monitoring compliance with CRA agreements.
\end{abstract}




\section{Introduction}

The past several decades have seen ongoing concerns raised about the adequacy of access to credit for lower-income and minority communities. In response, various legislative actions have been taken to try to correct perceived inequities. In 1977, the Community Reinvestment Act (CRA) was signed into law with the specific intent of encouraging federally-insured banking institutions to help meet the credit needs of borrowers in all segments of the communities within their service areas. The CRA was particularly concerned with those communities believed to have been historically under-served by the financial services industry, notably lower-income communities. The CRA has resulted in increased regulatory scrutiny of a banking institution's lending to lower-income communities, the public release of an institution's CRA performance rating, and the possible denial or delay of an institution's application for a merger or acquisition.

Although not exp licitly covered by the CRA, minority communities have been the subject of considerable concern on these issues as well. In this regard, fair lending laws, such as the Fair Housing Act and the Equal Credit Opportunity Act, have provided a legal structure for combating and eliminating race-based discrimination in credit markets. Consequently, lending to these communities has also been closely scrutinized, with banking institutions facing potential legal action if noncompliance with these laws is demonstrated.

The potential negative effects associated with having poor records of lending to lowerincome and minority communities have been one factor in motivating institutions to take 
affirmative steps to demonstrate or affirm their commitment to serving these communities. Also, community organizations have attempted to leverage these tools to increase the financial support from lending institutions for lower-income and minority communities. One intersection of these two efforts has been the increased prevalence of CRA agreements, which typically involve pledges to extend a certain volume of loans to targeted groups and communities. Since the early 1980's, community organizations and financial institutions have entered into over 300 CRA agreements, spanning nearly every state in the United States, and the dollar amount of CRA agreement pledges has increased dramatically over this period.

From an analytical perspective, there are at least two ways to assess the effects of CRA agreements. The first is to cons ider whether CRA agreements lead to changes in the lending behavior of institutions, either those that entered into agreements or those not involved in them. This is the general approach taken by Schwartz (1998b) and Bostic and Robinson (2000). Schwartz (1998b) finds that banks with CRA agreements increase the proportion of their lending activity in their service area that is directed at lowerincome and minority populations. Bostic and Robinson (2000) examine whether CRA agreements are associated with a redistribution of lending away from small, community lenders and find evidence to this effect.

The second approach, which is taken in the current research, is to consider the broader impact of CRA agreements by examining whether the presence of agreements is associated with changes in lending outcomes for the market as a whole. This research 
asks whether CRA agreements, either through their presence, number, introduction, or expiration, are associated with changes in lending activity to lower-income and minority communities in the areas where they are initiated. This is a critical argument, as presumably an important goal of pursuing these arrangements is to increase the total amount of lending to the targeted groups. If CRA agreements simply result in a redistribution of targeted lending among lenders or loan types (for example, a substitution between conventional and government-backed loans) with no net increase, then their efficacy could be questioned.

We consider this broader issue using a county-level panel constructed from county data on CRA agreements, economic and demographic experiences, and total mortgage lending activity. Empirical tests show that the number of new CRA agreements introduced in the intervening years in 3-year time intervals is found to be associated with growth in conventional mortgage lending activity to lower-income and minority communities and individuals, and with growth in mortgage lending overall. The results are consistent with the view that the increases represent new lending, although the evidence also suggests these increases are relatively short-lived, having a duration of less than 2 years. No relationships are observed between CRA agreements and changes in government-backed lending. Overall, these results are consistent with the notion that lenders view CRA agreements as a form of insurance against potentially large and unknown costs of fair lending violations and poor CRA performance ratings. The results are also consistent with the view that the effectiveness of CRA agreements in increasing lending activity is 
ultimately determined by the persistence and sophistication of community groups in monitoring compliance with CRA agreements.

The next section discusses in more detail the CRA, the genesis of agreements, and reasons why one might expect CRA agreements to influence lending patterns. Following this is a discussion of the empirical approach used to address this issue. Results and a concluding section follow.

\section{Regulation, CRA Agreements, and Lending}

Several government regulations of banking activity focus on the availability of credit to lower-income and minority borrowers and neighborhoods. The Community Reinvestment Act of 1977 (CRA) was intended to encourage banks to help meet the credit needs of all populations in their service area. The primary goal of this regulation is to ensure that low- and moderate-income individuals have adequate access to financial products and services. ${ }^{1}$ In addition, a number of fair lending laws, including the Equal Credit Opportunity Act (ECOA) and the Fair Housing Act, establish a regulatory framework for detecting and eliminating discrimination in housing and credit markets. The performance of banking institutions regarding these laws is assessed by federal regulators who periodically review the performance of federally-insured lenders with respect to compliance with fair lending laws and the record of these lenders in meeting CRA objectives. These examinations assess an institution's performance in serving its entire service area, including a review of mortgage and small business lending and bank branching patterns. If fair lending violations are found, banking institutions may face sanctions, including reimbursement for damages. Regarding the CRA, an examination 
results in a publicly-released CRA performance rating, which is a grade measuring the degree to which institutions have met CRA objectives. In addition, regulators use CRA ratings when reviewing applications for branch expansions and mergers.

Clearly, fair lending violations have adverse effects on banks. Poor CRA performance can also have negative effects for lenders as well. A bank that has a poor CRA rating is more likely to be targeted by the press and community groups for their lack of financial commitment to their service area. The potential for negative press and criticism by community-based organizations that can follow a poor CRA rating may serve as an incentive for banking institutions to direct additional resources to targeted communities and individuals within their service area.

Furthermore, an institution that wishes to expand its banking presence may have its application for a merger or branch expansion denied or delayed because of a poor CRA rating. Regulators may need more time to scrutinize the application of a poorly performing institution and banks with poor CRA records may be more likely to face challenges from community groups on CRA grounds. These protests can lead to considerable negative publicity for the bank and may require the use of significant bank resources to address particular allegations. Given the pace of consolidation in recent years, the demonstration of a commitment to and compliance with the CRA and fair lending laws has become a more salient issue. 
An increasingly common means for lending institutions to demonstrate their commitment to and compliance with CRA and fair lending laws has been to enter into agreements with community groups and other entities to help ensure the flow of credit throughout their service area. Table 1 shows that the volume of loan pledges associated with these agreements, referred to as "CRA agreements" in this paper, have grown since the passage of the CRA. CRA agreements often include explicit lending level targets to lowerincome and minority neighborhoods and individuals, while some also include non-credit provisions, such as the establishment of bank branches and investment in communitybased projects. Pledges typically specify a target geographic area, such as a neighborhood, city, or county, and then a particular population within that geographic area, such as lower-income or minority communities or borrowers. More recently, lenders have begun to make voluntary lending pledges in which they commit to lend to targeted communities without explicitly signing an agreement with a specific community group or other organization. Schwartz (1998a) provides a thorough review of the elements of CRA agreements.

An important feature of CRA agreements is that, although inspired by incentives created by federal government regulation, they technically lie outside of the regulatory framework and therefore do not represent government policy. CRA agreements almost exclusively involve lending institutions and community-based organizations; governmental entities are not generally involved. ${ }^{2}$ In addition, federal regulatory agencies do not encourage institutions to enter into agreements or monitor lending activity associated with individual agreements. CRA agreements, thus, qualitatively differ from 
government activities designed to increase lending to lower-income and minority populations. For example, the Department of Housing and Urban Development establishes annual affordable housing goals for Fannie Mae and Freddie Mac and then monitors their activities to determine the extent to which the goals are met. No comparable government monitoring mechanism exists to ensure compliance with CRA agreement pledges. The only monitoring of lending activity that typically takes place under CRA agreements is by the community groups that entered into the agreements with the lenders.

That said, CRA agreements can not be viewed as being completely unrelated to other government programs designed to increase the supply of mortgage credit to lowerincome and minority borrowers. For example, affordable housing goals have induced Fannie Mae and Freddie Mac to establish programs in which they purchase loans from lenders that would not be eligible for purchase on the secondary market using their typical underwriting standards. The ability of lenders to dispose of mortgages in this manner might increase the willingness of lenders to enter into agreements that involve loans with such non-standard characteristics.

Moreover, although they fall outside the formal regulatory framework, CRA agreements can complement government activities in this area. Often, the activities prescribed by CRA agreements can help institutions meet the objectives of government regulations designed to increase the flow of credit to lower-income and minority communities. For example, a loan originated to fulfill a CRA agreement pledge might also help a lender 
meet its CRA regulatory obligations and, if sold, could help a GSE meet its affordable lending goals.

From the perspective of community-based organizations, the objective of most CRA agreements is to induce lenders to commit a certain, and presumably increased, level of an institution's resources to targeted areas within the bank's service area with the goal of increasing lending activity in the targeted neighborhoods. This paper assesses the degree to which this may be occurring by determining if CRA lending agreements are associated with changes in mortgage lending activity in targeted communities.

\section{The Influence of CRA Agreements on Lending - Theoretical Predictions}

In a perfectly competitive market with no informational externalities, all loans for which marginal revenue exceeds marginal cost will be extended in equilibrium. Defining creditworthiness as having a sufficiently low probability of default such that the loan's expected return remains positive (profitable) in expectation after accounting for the costs of loan origination, this is equivalent to saying that all creditworthy borrowers receive loans in a perfectly competitive equilibrium.

Theory suggests that, in such an environment, a CRA agreement will have no impact on the amount of lending in a market. ${ }^{3}$ To see this, first recognize that the presence of a CRA agreement will not change the quantity of creditworthy borrowers. Thus, if the costs associated with loan origination have not changed, no additional loans will be extended in equilibrium. The only issue is how loans will be allocated among lenders. CRA agreements could lead to a redistribution of loan originations such that the lender 
involved in the agreement increases its lending at the expense of other market participants. This could occur if, for example, some borrowers select among lenders based on characteristics such as community involvement. ${ }^{4}$

On the other hand, a CRA agreement could increase the amount of lending in a market if informational externalities or other market failures exist. As shown in Stiglitz and Weiss (1981), Gruben, Neuberger, and Schmidt (1990), and Lang and Nakamura (1991), among others, market imperfections or failures can lead to credit-rationing, in which borrowers that would be deemed creditworthy in a perfectly-competitive, full-information environment do not receive credit. In one scenario, information imperfections in the market result in lenders being more uncertain about the true underlying risks associated with potential borrowers from certain populations. This increased uncertainty is incorporated into the lenders' underwriting decisions as increased variance in returns, which implies lower expected risk-adjusted returns from loans to those populations if the lender is risk averse. Lenders will therefore increase the underwriting threshold for these populations and ration credit. Rationing outcomes are also reached in the event that some lenders have market power or if market failures, discrimination, or other noninformational market imperfections exist, although the precise mechanism varies in each case.

CRA agreements can reduce the amount of credit rationing in lending markets if they serve to reduce informational or other market imperfections, market power, discrimination, or other market failures. Continuing with the imperfect information 
example, the experience lenders gain as a result of the additional lending induced by CRA agreements could reduce the uncertainty regarding the risk that borrowers from particular groups represent. If so, the expected risk-adjusted returns from loans to these borrowers would be closer to the expected returns in a perfectly-competitive, fullinformation environment, with a net result of less rationing. ${ }^{5}$

Another information-based story is that CRA agreements could cause lenders to discover profitable lending prospects among borrowers previously believed to be uncreditworthy. This could occur if agreements induce participating lenders to develop new and innovative products that use alternative methods for assessing credit risk that identify creditworthy potential borrowers that were not viewed as creditworthy using more traditional assessment approaches. While discoveries of new markets could result in increased lending by agreement participants, competitive forces could lead to similar lending increases by other non-participating lenders and potential entrants as well. ${ }^{6}$

There is yet another mechanism by which CRA agreements might increase lending. One might view CRA agreements as a type of "insurance" against the potentially large but uncertain costs associated with CRA-related challenges. By this argument, lenders incur a known cost associated with meeting CRA agreements, which is presumably smaller in expected value and utility than the costs of CRA-related challenges, with the result of substantially reducing the probability of facing a challenge. The probability of facing a challenge is reduced in two ways. First, negative press and other difficulties associated with poor CRA ratings will be reduced by fulfilling pledges outlined by the CRA 
agreement. Second, the likelihood that an institution will face a community-based challenge to its merger or other application on CRA grounds will be reduced because the institution will have already shown a willingness to accommodate and advance the relevant community interests.

If CRA agreements represent a form of "insurance," then one would expect lending institutions to enter them only in those instances when insurance was needed. There are at least two possibilities. If an institution was only concerned about challenges to merger or branching applications, one would expect only those institutions considering such actions in the near future to enter into agreements and that such agreements would expire shortly after the application was completed. In such a case, one would expect to observe increased lending during the life of the agreement, with an associated decline to preagreement lending levels after the agreement expired. On the other hand, if institutions were also concerned about difficulties associated with poor CRA performance ratings, then lending activity associated with agreements may remain relevant for longer periods. If so, then one would expect to observe agreements that did not expire or agreements that are periodically renewed on a routine basis. ${ }^{7}$ In this case, one would expect to observe increased lending from the inception of the agreement moving forward.

\section{Testing for the Influence of CRA Agreements on Lending}

The empirical tests focus on mortgage lending because data are not generally available for other types of lending. To determine the relationship between CRA agreements and patterns of mortgage lending, we develop a panel-based model that examines how the growth in mortgage lending in a specific geographic area varies with the presence, 
number, introduction, and expiration of CRA agreements in that area. We use the county, as opposed to the metropolitan statistical area, as the relevant geographic demarcation for two reasons. First, federal CRA and fair lending examiners typically assess a lender's performance at the county level. Second, most of the CRA agreements in our data are targeted at communities that are significantly smaller than MSAs. For most agreements, the use of a large geographic area like an MSA is inappropriate and would bias the analysis against finding that CRA agreements affect mortgage lending activity. Many CRA agreements target geographies even smaller than a county. Unfortunately, longitudinal data of the form needed for this analysis is not typically available for geographies smaller than a county. In this respect, the county represents a balance of competing considerations.

\section{Sample Description and Data Sources}

The best available national data that can be used to assess the influence of CRA agreements on total mortgage lending in a given geography are the data collected pursuant to the Home Mortgage Disclosure Act (HMDA). Since 1990, provisions in the HMDA have required that most institutions with offices in metropolitan areas provide detailed information on every application for a home mortgage that they receive over a year. For the purposes of the current research, the relevant data items are application disposition (approved, denied, withdrawn), type of mortgage (conventional, governmentbacked), location of the property, and borrower race or ethnicity and income. With this information, it is possible to determine the volume of conventional and governmentbacked mortgage lending to minority populations, to lower-income populations, and overall by county. 
Information on CRA agreements was gathered from the National Community Reinvestment Coalition (NCRC). NCRC is a trade association of more than 800 community groups and local public agencies that focuses on CRA-related issues. Each year, NCRC updates its list of all CRA agreements known to NCRC by surveying its membership and reviewing media accounts of CRA agreements. ${ }^{8}$ Where possible, NCRC obtains hard copies of the agreements negotiated between its members and lending institutions. Information was collected from these hard copies specifying the types and amounts of lending pledges, the targeted group or community, whether non-lending technical assistance is being provided, the duration of the agreements, and the years the agreements are active. The agreements provided by NCRC were used to identify those counties where an active CRA agreement was in place. However, not all CRA agreements initiated by NCRC members are included in the analysis. Specifically, the sample of agreements was restricted to those agreements that included a pledge for mortgage credit that could be tracked to a targeted community. ${ }^{9}$

The mortgage lending and agreement data are supplemented with non-lending variables characterizing economic and demographic conditions within counties available from the Regional Economic Information Service (REIS) of the Bureau of the Census. These data provide population, employment, and income information at the county level.

With data from these three sources, we constructed a panel of counties. Counties were restricted to those located in metropolitan statistical areas (MSAs) and were required to 
appear in the HMDA data in every year from 1993 to $1999 .{ }^{10}$ The analysis only considers lending after 1993, because the HMDA criteria for determining those institutions that were required to report on their mortgage applications changed in 1993. The changes were such that the population of reporters since 1993 is much broader than the population of reporters from 1990 to $1992 .{ }^{11}$ The final sample includes 727 counties in metropolitan areas over 7 years. Table 3 provides a profile of our panel.

Table 4 uses the 1994 data to demonstrate the considerable diversity in county initial conditions and subsequent experiences in the data. Levels of lending, the presence of CRA agreements, population, income and earnings data show that the counties in the sample range from very large to very small and from relatively affluent to less so. This diversity in condition and experience, which is present in all years of the panel, is important for the empirical tests, as they provide the opportunity to distinguish among competing explanations for observed changes in lending. In addition, the data in tables 3 and 4 are consistent with other research that has found that CRA and minority lending increased relative to other types of lending during the 1990s. ${ }^{12}$ This suggests that the county restriction has not resulted in a sample that is qualitatively different from the general population.

The data show that counties with agreements were quite different from those without agreements. Table 5 compares counties according to whe ther they had an active CRA agreement, using 1994 as an example. Counties with agreements tended to be larger and more affluent than those without agreements. In addition, counties with agreements grew 
slightly faster on average over the ensuing 3 years in terms of population, employment, income, and earnings than counties without agreements. In spite of this faster growth, counties with agreements had relatively small growth in conventional mortgage lending, with the average growth rates in lending in counties with agreements only a fraction of the average lending growth rates in counties without agreements. No significant differences across counties were observed in the growth of government-backed mortgage lending.

These relationships suggest that CRA agreements are unlikely to be associated with lending growth. For conventional mortgage lending, if they suggest anything, the implication is that CRA agreements might be associated with relative declines in lending. However, table 5 only provides a univariate analysis of the data, which can be misleading if there are important correlations among county characteristics. The next section develops a multivariate model that can be used to account for these correlations.

\section{A Multivariate Model}

The multivariate empirical model used in this study relates the 3-year growth in mortgage lending in a county to county characteristics, the presence of CRA agreements, and changes in these factors. Using our panel of counties, we estimate a standard fixedeffects model with a time trend,

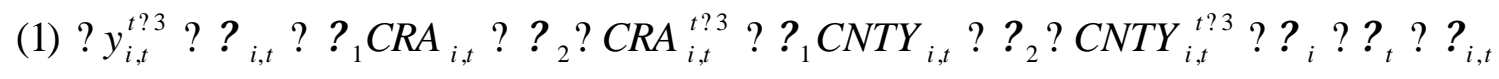

where $? y_{i, t}^{t ? 3}$ is the percentage change in the number of loans originated in county i over period $\mathrm{t}$ to $\mathrm{t}+3, C R A_{i, t}$ is a vector of variables characterizing the CRA agreements in the 
county at time t, ?CRA $A_{i, t}^{t ? 3}$ is a vector of variables describing the changes in the number of CRA agreements in the county between $\mathrm{t}$ and $\mathrm{t}+3, C N T Y_{i, t}$ is a vector of county characteristics at time t, ? $C N T Y_{i, t}^{t ? 3}$ is a vector of variables indicating the changes in the county characteristics from $\mathrm{t}$ to $\mathrm{t}+3, ?_{i}$ is the vector of county-level fixed effects, and $?_{t}$ is a vector of year dummy variables. This model assumes that the within-county residuals are independently and identically distributed.

\section{Dependent Variables}

The dependent variable, ? $y_{i, t}^{t ? 3}$, is the percentage change in the number of mortgage loans originated over a 3 -year interval, calculated as $\frac{\left(y_{i, t} ?^{2} ?_{i, t}\right)}{y_{i, t}}$. So while the baseline data include 727 counties over 7 years, the data used in the multivariate estimation include only 4 years worth of information for each county. A three-year interval was chosen because it was believed that any effects that CRA agreements might have on lending would be unlikely to be fully realized over shorter time intervals. Indeed, the hypothesized mechanisms by which agreements reduce market imperfections and failures are likely to require some time to have a market impact.

Because CRA agreements usually focus on those communities believed to have been underserved historically, typically lower-income and minority communities, the analysis focuses on three categories of mortgage lending: all lending, lending to lower-income borrowers and neighborhoods (CRA lending), and lending to minority borrowers and neighborhoods (minority lending). Overall lending is considered to establish whether 
observed effects on CRA and minority lending represent new lending or a substitute away from lending to other groups.

The majority of CRA agreements focus on conventional mortgage lending. Therefore, equation (1) is estimated separately for the three categories of conventional lending (total, CRA, and minority). Government-backed lending, lending insured by the Federal Housing Administration (FHA), Veterans Administration (VA), or the Rural Housing Administration (RHA), is also of interest for this research because CRA agreements target populations that disproportionately obtain government-backed loans. Given this, conventional lending resulting from CRA agreement activity could substitute for government-backed lending. We therefore also estimate equation (1) for the three categories of government-backed lending. Because of our focus on metropolitan areas, the government-backed lending in the current analysis is primarily FHA- and VA-backed.

\section{Explanatory Variables}

The variables in CNTY represent the initial economic conditions within the county, which can influence growth rates in mortgage lending. ${ }^{13}$ These include county population (POP), employment (TOTEMP), income (TOTINC), total earnings (TOTERN), earnings per employee (PJEARN), and per capita income (PCINC). The initial level (number of loans) of each type of lending (LENDT) is also included as an independent variable in the relevant regression to control for differences in the scale of lending across counties in the sample. 
The model also includes a number of variables to account for changes in lending activity that may arise due to changes in county characteristics (the ?CNTY vector). Changes in lending are modeled to also be a function of changes in county population (DPOP3), total earnings in the county by place of work (? TARN3), total employment in the county (DEMP3), earnings per job in the county (DPJEARN3), and per capita income in the county (DPCINC3). A reasonable assumption is that lending will grow faster in those counties with the largest growth in population, employment, and income. The use of independent variables that track changes over the same period as the dependent variables introduces the possibility of simultaneity bias in the estimates. However, in the current context, we view it as implausible that the growth in mortgage lending activity would precede population, employment, or income growth. It is much more likely that population or economic growth spurs growth in the demand for homes, which in turn leads to an increase in mortgage lending. ${ }^{14}$

As this is a panel, we further include county-level fixed effects. These allow us to account for any county-specific effects not captured by the other county-level variables in the specification. ${ }^{15}$ Similarly, we include year dummy variables to account for systematic differences in lending levels and growth across the years of our sample.

The key independent variables involve CRA agreements. PRES0 is a binary variable that equals one if the county had an active CRA lending agreement in place in the initial year and zero otherwise. A CRA agreement was considered to be active in a given year if it was in effect for more than half the year. ${ }^{16}$ The sign on the coefficient for PRES0 
indicates whether the initial presence of an active agreement is associated with subsequent changes in lending. For example, a negative coefficient would indicate that growth in lending is less in counties that initially had at least one active CRA agreement.

AGR0 indicates the number of CRA agreements that were active in a county in the initial year. This variable focuses on whether any observed effects of CRA agreements vary with the number of agreements that are active. For example, a positive sign for the coefficient on AGR0 would indicate that lending growth is increasing in the initial number of agreements that are active in the county. Another variable used to measure the scale of CRA agreement activity during the period is the volume of dollar pledges associated with CRA agreements.

While PRES0 and AGR0 describe CRA agreement activity in the initial year, the third set of key independent variables indicate the number of agreements that became active during each of the intervening years of the 3-year interval. We construct three variables-NEWYR1, NEWYR2 and NEWYR3 - that indicate the number of new CRA agreements that became active in the first, second, and third years of the 3-year interval, respectively. The sign of the coefficients on these variables shows how the number of new active CRA agreements in a county is associated with changes in lending activity in that county during the entire 3-year interval.

The last CRA agreement variables of interest are YROFF0, YROFF1 and YROFF2. These variables represent the number of active CRA agreements that expire in the initial, 
first, and second years of the sample, respectively. These variables explore the impact on changes in lending activity associated with the expiration of CRA agreements in a county and can help shed light on the "insurance hypothesis" introduced above. All variables are listed in table 2.

\section{$\underline{\text { Treatment of other targeted lending programs }}$}

An additional issue involves the treatment of other programs designed to increase targeted lending. We noted earlier that the presence of such programs might influence lender willingness to enter into CRA agreements and thus might be important when considering the impact of CRA agreements. Ideally, our specification would account for these factors. However, the majority of these programs are national in nature and applied identically across all of the counties in our sample (and across the entire country). This feature makes the empirical identification of their marginal effects on lending and, importantly, the differences in these effects across counties virtually impossible, and so we do not include measures such as Fannie Mae and Freddie Mac activity in our specification.

\section{Results}

\section{Conventional Mortgage Lending}

Table 6 shows the regression estimates of equation (1) for each of the three conventional mortgage lending categories. For each regression, the coefficients on the CRA agreement variables show if the presence, number, introduction, or expiration of CRA agreements in a county is associated with subsequent changes in lending in that county. 
The estimates show that it is primarily through the introduction of new agreements in a county, and not through the presence, number, or expiration of agreements, that CRA agreements affect conventional mortgage lending patterns. New agreements initiated in the second and third years of a 3-year interval were significantly associated with increases in total, CRA, and minority conventional lending in a county. Although the coefficient estimates indicate larger effects for minority lending, because minority lending had the largest increases generally, the effects are proportionally the same for each type of lending. A CRA agreement initiated in the second year of a 3-year interval is associated with an increase in the growth rate of conventional mortgage lending of roughly 20 percent. A new agreement initiated in the final year of a 3-year interval is associated with about 14 percent higher growth in lending. Further, the positive relationship observed for total conventional lending suggests that the additional lending represents some new lending and not simply a substitution of targeted lending in lieu of lending to other groups.

Other CRA agreement variables were generally not significantly associated with growth in lending. The lone exception is YROFF3, which was positively associated with growth in total conventional mortgage lending. This runs counter to the expectation that the expiration of an agreement would result in a return to lower pre-agreement levels of lending, which suggests a negative relationship. Perhaps this reflects a substitution effect between targeted and more general lending. Upon the expiration of an agreement, lenders might redirect resources previously focused on meeting agreement pledges toward extending non-targeted conventional mortgages. If true, one might have expected 
other YROFF variables to show significant relationships with growth in total conventional lending, which is not observed. Point estimates for the coefficients on the other YROFF variables are, in fact, positive and relatively large, but the large variation in experiences across counties and years prevents a rejection of the null hypothesis that the coefficients equal zero. An alternative potential explanation is that a CRA agreement causes lenders to increase their attention towards those markets in which the agreement covers and that this increased attention persists beyond the life of the agreement.

Considered together, the results for the NEWYR variables are consistent with the notion that institutions quickly increase conventional mortgage lending in areas with a newly active CRA agreement, but that these increases are relatively short-lived. Recall that the coefficients on the CRA variables for the intervening years represent cumulative effects. The significant coefficients imply that the first year an agreement is active is associated with a large increase in lending (about 14 percent) and the second year with a smaller increase in lending (estimated at approximately 6 percent). However, the insignificant (and negative) coefficients on the presence variable suggests that the subsequent years in the life of agreements are associated with very small growth (contraction) in lending, which over time significantly dampens the effects of the initial increases in lending.

A number of county characteristics were also found to have significant relationships with changes in conventional mortgage lending. The data indicate convergence in lending over time, as lending tended to grow more quickly in counties that experienced less lending initially. As expected, growth in lending tended to be positively associated with 
initial levels of total income and per capita income. The results also suggest an earningsbased convergence in activity, as growth in lending was faster in counties with lower initial levels of total earnings. Among the change variables, the significant relationships conformed to expectations, as growth in lending was greater in counties with more growth in employment and income. Two relationships were significant only for the total conventional lending estimate. The positive relationship between initial population and growth in lending was expected. By contrast, the negative relationship between changes in lending and changes in earnings in a county was not.

\section{Government-backed Mortgage Lending}

Table 7 shows a similar analysis for government-backed lending. Unlike the case for conventional mortgage lending, no CRA agreement-related variables are significantly related to changes in lending when government-backed lending is considered. Only the positive coefficient on the variable representing the initial number of active agreements in the county in the CRA lending regression approaches statistical significance. Overall, the model did not perform as well in describing relationships for government-backed lending as compared to conventional mortgage lending, as few control variables were found to have significant relationships with changes in lending.

It is worth noting that the lack of significance is not surprising. Most CRA agreements do not include specific lending targets for government-backed loans. Rather, most agreements involve commitments to promote institution-specific products that typically do not have go vernment involvement. It was therefore expected that, at most, an indirect relationship between changes in government-backed lending and CRA agreements would 
exist. However, the divergence in results for conventional and government-backed lending does suggest that the conventional lending relationships are not simply the result of omitted economic factors but rather reflect significant economic relationships.

\section{Robustness of Conventional Results}

To verify the robustness of the results, we conducted a number of additional analyses. Equation (1) was first estimated substituting changes in loan dollars for changes in the number of loans as the dependent variable. We also conducted separate estimates substituting percentage changes in county characteristics for the raw number changes used in the baseline specification. Further, we estimated equation (1) for 2-year intervals. The results of these estimates (not shown) were effectively equivalent to those presented and are therefore not discussed. For all three loan categories (all, CRA, and minority), CRA agreements introduced in the intervening years of the analytical period are positively associated with growth in the number of conventional loans originated in a county. Moreover, the finding that growth in total conventional lending is positively associated with the expiration of agreements in the last year of the time interval also is consistently observed.

The lone deviation from the 3-year results is the finding that, after controlling for other factors, the presence of CRA agreements is significantly negatively associated with 2year changes in conventional CRA lending. The coefficient on the presence of CRA agreements in a county for the 3-year analysis of conventional CRA lending is similarly negative, but the substantial variation in county experiences prevents us from drawing a conclusion that the effect is robust. That this variable is not statistically significant in the 
3-year estimate suggests that our concern that analyses over short time intervals might negatively bias estimates may be well-founded. The increased variance in the 3-year estimates suggests that the effects of some agreements only appear after longer periods of time.

\section{Conclusion}

Entering into CRA agreements is one way some banking institutions have chosen to demonstrate or affirm their commitment to serving lower-income and minority communities and for community organizations to leverage existing laws to increase the financial support lending institutions extend to those communities. Economic theory does not provide unambiguous predictions regarding the likely effect of CRA agreements on lending. Under different assumptions, agreements can theoretically increase, decrease, or have no effect on lending.

This paper empirically examines this question. Beginning from an empirical framework that models changes in aggregate lending as a function of local economic characteristics and changes in those characteristics, the analysis examines the relationship between CRA lending agreements and the change in mortgage lending activity over 3-year intervals. The analysis uses county-level panel data constructed using HMDA data on mortgage lending activity, REIS data on county-level economic and demographic characteristics, and data on CRA agreements compiled from the NCRC. Regressions are run separately by type of loan product (conventional versus government-backed) and by loan category (total, CRA, or minority). 
The key result is that, of the several variables characterizing CRA agreements in a county, only the number of newly-initiated CRA agreements in a county was found to be significantly associated with 3-year changes in conventional mortgage lending. Newly initiated agreements were found to be associated with significant increases in total lending in a county, a result that held for CRA, minority, and overall conventional mortgage lending. The results for CRA and minority lending are consistent with the view that institutions increase targeted conventional mortgage lending upon the introduction of a CRA agreement. The fact that total lending also increases implies that the increased targeted lending is new lending, and lending that is not substituted from other groups. Moreover, these results show that these increases in lending are relatively short-lived. Finally, no CRA agreement-related variables were found to be significantly associated with changes in government-backed lending.

The results are broadly consistent with the notion that lenders view CRA agreements as a form of insurance against the potentially large and uncertain costs of fair lending violations, poor CRA performance ratings, and adverse publicity from CRA-related protests of mergers or other applications. Lenders enter into agreements and soon thereafter increase their targeted lending to build a positive CRA record. The evidence suggests that the increase in targeted lending is short-lived implying one of two possibilities. First, lenders might only need the "insurance" for a short period of time, such as during the course of a merger or other application, and alter their behavior only during this time. Indeed, Evanoff and Segal (1996) and Bostic, Mehran, Paulson, and 
Saidenberg (2000) find similar evidence suggesting that lenders alter their CRA-related activities in anticipation of CRA performance reviews and merger applications.

Second, it could be that the community organizations that enter into the agreements have limited monitoring capabilities, and that after a short period of relatively intense scrutiny it becomes increasingly unlikely that a lender will face adverse publicity for not meeting agreement pledge goals. In this view, the decline in additional lending over time corresponds to a decline in the likelihood that non-compliance with agreement pledges will be detected by community organizations that often have limited resources to conduct effective and on-going monitoring of lender activities. The likelihood of detection declines as time passes because, as the organizations respond to new local issues and demands, they devote fewer resources to monitoring compliance with agreements. An implication of this perspective is that increases in lending activity are ultimately determined by the persistence and sophistication of community groups involved in monitoring compliance with CRA agreements.

In support of this view, Squires and O'Connor (2001) observe that lenders and community-based organizations have widely divergent resources at their disposal, which leaves community organizations at somewhat of a disadvantage, and advocate the need for bolstered community activism that focuses on maintaining engagement on issues that remain relevant over longer time periods. The implication is that the maintenance of engagement would correspond to persistent increases in lending. NCRC (2000) provides examples that support this perspective. 
Of course, a key consideration in either case is the profitability of the additional loans. The theoretical framework in this paper assumes an environment in which the lending market operates as an essential closed market. If the market can be influenced by realities in other markets, which is almost certainly the case, then other possibilities emerge. Most relevant in the current context is the possibility that lenders entering into CRA agreements may increase their targeted lending even in the absence of informational externalities or other market failures. This could occur if lenders extend new loans by subsidizing borrowers, presumably using proceeds from other markets in which the lender earns profits. In this instance, borrowers not meeting typical standards of creditworthiness receive loans and lenders would expect losses on these activities. Lenders might engage in subsidization to eliminate the possibility of even more costly negative publicity and other adverse outcomes that could theoretically arise if agreement targets were not met.

If the new loans identified in this research were not profitable, then CRA agreements would effectively be a subsidy from lenders to borrowers. A recent study by the Federal Reserve examined this question indirectly by conducting a survey that assessed the profitability of CRA-related lending considered broadly. In this research, 82 percent of the banking institutions that responded to the survey reported that their CRA lending was profitable. ${ }^{17}$ However, not all of the institutions that participated in the survey had entered into CRA agreements and not all loans considered to be CRA-related in the survey were extended as a direct result of CRA agreements. 
However, if the Federal Reserve findings are believed, other questions arise. If the additional lending was profitable, economic theory predicts that lenders would continue to extend loans at the increased levels to the targeted communities. Yet this is not what is observed. One must wonder why lenders would choose to stop extending the additional loans to communities that have demonstrated profitable lending opportunities. Future research on the patterns of lending by those institutions that enter into CRA agreements and the profitability of such lending is needed to shed more light on these issues.

Finally, while the analysis in this study has carefully considered the effects of CRA agreements on targeted lending, it has not focused on other programs that have targeted lending to lower-income and minority borrowers as an objective. Such programs, including those established by Fannie Mae and Freddie Mac in response to HUD's affordable goals, the Campaign for Homeownership by the Neighborhood Reinvestment Corporation, and those undertaken by lenders as an independent response to the CRA, undoubtedly play an important role in this area. A complete understanding of how policy affects targeted lending will require analysis of the impacts of these efforts as well.

The views expressed are not necessarily those of the Board of Governors of the Federal Reserve System or its staff. The authors would like to express extreme gratitude to Joshua Silver and the National Community Reinvestment Coalition for providing us with access to their data on CRA agreements. In addition, we thank Melissa Mugharbel and Jennifer Attrep for providing invaluable research assistance and Glenn Canner, Geoffrey Tootell, and anonymous referees for insightful comments. 


\section{References}

Avery, R.B., and R.W. Bostic, P.S. Calem and G.B. Canner. 1999. Trends in Home Purchase Lending: Consolidation and the Community Reinvestment Act. Federal Reserve Bulletin 85(2): 81-102.

Board of Governors of the Federal Reserve System. 2000. The Performance and Profitability of CRA-related Lending, report submitted to the Congress pursuant to the Gramm-Leach-Bliley Act of 1999.

Bostic, R.W., J.S. Gans and S. Stern. 1997. Urban Productivity and Factor Growth in the Late Nineteenth Century. Journal of Urban Economics 41: 38-55.

Bostic, R.W., H. Mehran, A.L. Paulson, and M. Saidenberg. 2000. Community Lending and Commercial Bank Mergers. Proceedings of the 2000 Conference on Bank Structure and Competition: 452-467.

Bostic, R.W. and B.L. Robinson, 2000, "Community Banking and Mortgage Credit Availability: The Impact of CRA Agreements," Unpublished working paper.

Evanoff, D.D. and L.M. Segal. 1996. CRA and Fair Lending Regulations: Resulting Trends in Mortgage Lending. Economic Perspectives: 19-46.

Gruben, W.C., J.A. Neuberger, and R.H. Schmidt. 1990. Imperfect Information and the Community Reinvestment Act. Federal Reserve Bank of San Francisco Economic Review Summer: 27- 46.

Lang, W.W. and L.I. Nakamura. 1993. A Model of Redlining. Journal of Urban Economics 33: 223-234.

National Community Reinvestment Coalition. 2000. CRA Commitments. NCRC: Washington, DC.

National Community Reinvestment Coalition. 2000. Doing Well by Doing Good: CRA Lending is Profitable for Banks and Critical for Communities. NCRC: Washington, DC.

Schwartz, A. 1998a. From Confrontation to Collaboration? Banks, Community Groups, and the Implementation of Community Reinvestment Agreements. Housing Policy Debate 9(3): 631-662.

Schwartz, A., 1998b. Bank Lending to Minority and Low-Income Households and Neighborhoods: Do Community Reinvestment Agreements make a Differences? Journal of Urban Affairs 20(3): 269-301. 
Squires, G.D. and S. O'Connor, 2001, Color and Money: Politics and Prospects for Community Reinvestment in Urban America, Albany: SUNY Press.

Stiglitz, J.E. and A. Weiss, 1981, "Credit Rationing in Markets with Imperfect Information," American Economic Review, 71(3), 393-410. 
Table 1. Annual CRA Agreement Dollar Pledges, in millions of dollars

\begin{tabular}{|c|c|c|}
\hline$\underline{\text { Year }}$ & Annual Amount & Cumulative Amount \\
\hline 1999 & 32,377 & $1,085,176$ \\
\hline 1998 & 696,270 & $1,052,799$ \\
\hline 1997 & 221,345 & 356,529 \\
\hline 1996 & 49,678 & 135,184 \\
\hline 1995 & 26,521 & 85,506 \\
\hline 1994 & 6,123 & 58,985 \\
\hline 1993 & 10,474 & 52,862 \\
\hline 1992 & 33,583 & 42,387 \\
\hline 1991 & 2,427 & 8,805 \\
\hline 1990 & 1,614 & 6,378 \\
\hline 1889 & 2,260 & 4,764 \\
\hline 1988 & 1,248 & 2,504 \\
\hline 1987 & 357 & 1,256 \\
\hline 1986 & 516 & 899 \\
\hline 1985 & 73 & 382 \\
\hline 1984 & 219 & 309 \\
\hline 1983 & 1 & 90 \\
\hline 1982 & 6 & 89 \\
\hline 1981 & 5 & 83 \\
\hline 1980 & 13 & 78 \\
\hline 1979 & 15 & 65 \\
\hline 1978 & --- & 50 \\
\hline 1977 & 50 & 50 \\
\hline
\end{tabular}

Source: Data compiled by the National Community Reinvestment Coalition 
Table 2. Variable List

Dependent variables

? TOTLEND Percentage change in the total number of mortgage loans originated in the county over the 3-year interval

? CRALEND Percentage change in the number of mortgage loans originated to lower-income applicants in the county over the 3-year interval

? MINLEND Percentage change in the number of mortgage loans originated to minority applicants in the county over the 3-year interval

$\underline{\text { Independent variables }}$

PRES0

AGR0

NEWYR1

NEWYR2

NEWYR3

YROFF0

YROFF1

YROFF2

LENDT

TOTINC

POP

PCINC

TOTERN

TOTEMP

PJEARN

DTOTINC3

DPOP3

DPCINC3

DTOTERN3

DTOTEMP3

DPJEARN3

? INCPC
A binary variable equal to one if a CRA agreement exists in the county in initial year of the interval

Total number of active CRA agreements in county, initial year

Number of new CRA agreements in first year of interval

Number of new CRA agreements in second year of interval

Number of new CRA agreements in third year of interval

Number of CRA agreements that expired in initial year of interval Number of CRA agreements that expired in first year of interval Number of CRA agreements that expired in second year of interval

(Total lending in county, initial year)/1,000

(Total income in county, initial year)/10,000,000

(Total county population, initial year)/100,000

(Per capita income in county, initial year)/10,000

(Total earnings in county, initial year)/10,000,000

(Total employment in county, initial year)/100,000

(Total earnings per employed person in the county, initial year) $/ 100,000$

(Change in total in county over interval)/10,000,000

(Change in county population over interval)/100,000

(Change in per capita income in county over interval) 10,000

(Change in total earnings in county over interval)/10,000,000

(Change in total employment in county over interval)/100,000

(Change in total earnings per employed person in county over interval)/100,000

(Change in per capita income in county over interval)/10,000 
Table 3. Mean Values for County Characteristics, by year

\begin{tabular}{|c|c|c|c|c|c|c|c|}
\hline Variable & 1993 & 1994 & 1995 & 1996 & 1997 & 1998 & 1999 \\
\hline \multicolumn{8}{|l|}{ Level } \\
\hline \multicolumn{8}{|l|}{ Conventional loans } \\
\hline Total & 2287 & 2636 & 2489 & 2780 & 2776 & 3303 & 3433 \\
\hline CRA & 625 & 760 & 722 & 815 & 806 & 999 & 1116 \\
\hline Minority & 469 & 614 & 596 & 641 & 659 & 796 & 918 \\
\hline \multicolumn{8}{|l|}{ Govt.-backed loans } \\
\hline Total & 907 & 837 & 843 & 990 & 1020 & 1078 & 1152 \\
\hline CRA & 407 & 385 & 382 & 473 & 516 & 556 & 605 \\
\hline Minority & 302 & 315 & 333 & 397 & 420 & 448 & 498 \\
\hline CRA agreements & 0.49 & 0.46 & 0.52 & 0.75 & 0.78 & 0.91 & 0.89 \\
\hline Total income (\$mil) & $6,386.370$ & $6,696.769$ & $7,069.545$ & $7,460.592$ & $7,912.183$ & $8,452.802$ & $8,930.069$ \\
\hline Population & 275,974 & 278,636 & 281,136 & 283,734 & 286,594 & 289,427 & 292,287 \\
\hline Per capita income (dollars) & 20,541 & 21,430 & 22,335 & 23,321 & 24,498 & 25,826 & 26,897 \\
\hline Total earnings (\$mil) & $4,726.387$ & $4,945.074$ & $5,196.484$ & $5,481.157$ & $5,829.209$ & $6,265.571$ & $6,686.380$ \\
\hline Total employment & 157,147 & 160,863 & 165,012 & 168,791 & 172,933 & 177,786 & 181,984 \\
\hline Earnings per job (dollars) & 25,053 & 25,679 & 26,096 & 26,816 & 27,685 & 28,829 & 29,847 \\
\hline \multicolumn{8}{|l|}{ "3-year change(number) } \\
\hline \multicolumn{8}{|l|}{ Conventional loans } \\
\hline Total & 364 & 134 & 277 & 161 & $\ldots$ & $\ldots$ & $\ldots$ \\
\hline CRA & 508 & 234 & 386 & 307 & $\ldots$ & $\ldots$ & $\ldots$ \\
\hline Minority & 723 & 271 & 347 & 415 & $\ldots$ & $\ldots$ & $\ldots$ \\
\hline \multicolumn{8}{|l|}{ Govt.-backed loans } \\
\hline Total & 209 & 359 & 392 & 228 & $\ldots$ & $\ldots$ & $\ldots$ \\
\hline CRA & 317 & 520 & 672 & 414 & $\ldots$ & $\ldots$ & $\ldots$ \\
\hline Minority & 578 & 584 & 497 & 468 & $\ldots$ & $\ldots$ & $\ldots$ \\
\hline CRA agreements & 0.26 & 0.33 & 0.40 & 0.14 & $\ldots$ & $\ldots$ & $\ldots$ \\
\hline Total income (\$mil) & $1,074.222$ & $1,215.414$ & $1,383.257$ & $1,469.477$ & $\ldots$ & $\ldots$ & $\ldots$ \\
\hline Population & 7,760 & 7,958 & 8,291 & 8,553 & $\ldots$ & $\ldots$ & $\ldots$ \\
\hline Per capita income (dollars) & 2,780 & 3,068 & 3,491 & 3,576 & $\ldots$ & $\ldots$ & $\ldots$ \\
\hline Total earnings (\$mil) & 754.769 & 884.135 & $1,069.087$ & $1,205.224$ & $\ldots$ & $\ldots$ & $\ldots$ \\
\hline Total employment & 11,644 & 12,070 & 12,774 & 13,193 & $\ldots$ & $\ldots$ & $\cdots$ \\
\hline Earnings per job (dollars) & 1,763 & 2,006 & 2,733 & 3,031 & $\ldots$ & $\ldots$ & $\ldots$ \\
\hline
\end{tabular}


Table 4. County Characteristics, 1994

\begin{tabular}{|c|c|c|c|c|}
\hline Variable & Mean & Std Dev & Minimum & Maximum \\
\hline \multicolumn{5}{|l|}{ Initial Levels, 1994} \\
\hline \multicolumn{5}{|l|}{ Number of conventional loans } \\
\hline Total & 2636 & 4345 & 9 & 57700 \\
\hline CRA & 760 & 1254 & 2 & 19100 \\
\hline Minority & 614 & 2011 & 0 & 38364 \\
\hline \multicolumn{5}{|l|}{ Number of gov't-backed loans } \\
\hline Total & 837 & 1466 & 2 & 16798 \\
\hline CRA & 385 & 734 & 0 & 8839 \\
\hline Minority & 315 & 859 & 0 & 10153 \\
\hline CRA agreements & 0.46 & 1.21 & 0 & 8 \\
\hline Total income (\$mil) & $6,696.769$ & $13,102.003$ & 112.350 & $207,403.257$ \\
\hline Population & 278,636 & 518,825 & 5,726 & $9,048,139$ \\
\hline Per capita income $(\$)$ & 21,430 & 4,636 & 11,122 & 55,222 \\
\hline Total earnings (\$mil) & $4,945.074$ & $11,433.803$ & 26.778 & $168,070.144$ \\
\hline Total employment & 160,863 & 311,019 & 1,586 & $4,924,655$ \\
\hline Earnings per job (\$) & 25,679 & 5,269 & 13,685 & 57,051 \\
\hline \multicolumn{5}{|l|}{ Changes from 1994-1997 } \\
\hline \multicolumn{5}{|c|}{ Number of conventional loans, percent } \\
\hline Total & 0.13 & 0.29 & -0.38 & 2.0 \\
\hline CRA & 0.23 & 0.48 & -0.52 & 5.0 \\
\hline Minority & 0.27 & 0.59 & -0.86 & 5.5 \\
\hline \multicolumn{5}{|c|}{ Number of gov't-backed loans, percent } \\
\hline Total & 0.36 & 0.61 & -0.78 & 7.5 \\
\hline CRA & 0.52 & 0.89 & -0.78 & 17.5 \\
\hline Minority & 0.58 & 1.19 & -1.00 & 20.0 \\
\hline CRA agreements & 0.31 & 0.92 & -6.00 & 6.00 \\
\hline Total income (\$mil) & $1,215.414$ & $2,418.643$ & 13.948 & $27,671.669$ \\
\hline Population & 7,958 & 19,369 & $-67,910$ & 279,065 \\
\hline Per capita income $(\$)$ & 3,068 & 1,244 & -124 & 13,108 \\
\hline Total earnings (\$mil) & 884.135 & $2,354.004$ & 805.677 & $36,286.098$ \\
\hline Total Employment & 12,070 & 24,255 & $-29,100$ & 285,288 \\
\hline Earnings per job (\$) & 2,006 & 1,577 & $-16,436$ & 11,681 \\
\hline MEMO: Number of counties & 727 & & & \\
\hline
\end{tabular}


Table 5. Comparison of Counties with and without CRA agreements, 1994

\begin{tabular}{lrr} 
Variable & $\begin{array}{c}\text { Counties without } \\
\text { 1994 Agreements }\end{array}$ & $\begin{array}{r}\text { Counties with } \\
\text { 1994 Agreements }\end{array}$ \\
\hline Initial Levels, 1994 & & \\
Number of conventional loans & 2134 & $4878^{* *}$ \\
$\quad$ Total & 623 & $1369^{* *}$ \\
CRA & 409 & $1529^{* *}$ \\
$\quad$ Minority & & \\
Number of government-backed loans & 700 & $1449^{* *}$ \\
$\quad$ Total & 328 & $639^{* *}$ \\
CRA & 233 & $678^{* *}$ \\
$\quad$ Minority & 0 & 2.50 \\
CRA agreements & $5,351.028$ & $12,707.070^{* *}$ \\
Total income $(\$ m i l)$ & 223,402 & $525,316^{* *}$ \\
Population & 21,083 & $22,979^{* *}$ \\
Per capita income $(\$)$ & $3,933.142$ & $9,464.529^{* *}$ \\
Total earnings $(\$ m i l)$ & 129,681 & $300,124^{* *}$ \\
Total employment & 25,167 & $27,964^{* *}$ \\
Earnings per job $(\$)$ & &
\end{tabular}

Percentage change, 1994-1997

Number of conventional loans

Total

CRA

Minority

Number of government-backed loans

Total

CRA

Minority

CRA agreements

Total income $(\$)$

Population

Per capita income $(\$)$

Total earnings (\$)

Total employment

Earnings per job (\$)

MEMO: Number of counties
6.8

42.1

70.7

51.4

157.6

257.9

…

2.8

14.2

17.7

7.5

7.5

594
$1.7 * *$

$8.2 * *$

$12.4 * *$

$24.6^{* *}$

$83.6^{* *}$

$75.2 * *$

45.2

18.3

3.0

14.6

18.1

7.5

9.1

133

NOTE: Asterisks indicate a statistically significant difference between the values for counties with agreements and counties without agreements. $*_{-} \mathrm{p}<.01, *_{-} \mathrm{p}<.05$. 
Table 6. Conventional Mortgage Lending Regression Results

The dependent variables are, respectively, the percentage change in total, CRA, and minority conventional lending in a county over 3 years.

\begin{tabular}{|c|c|c|c|}
\hline \multirow{3}{*}{ AGR0 } & Total Lending & CRA Lending & $\underline{\text { Minority Lending }}$ \\
\hline & -0.036 & 0.006 & -0.004 \\
\hline & $(0.027)$ & $(0.055)$ & $(0.060)$ \\
\hline \multirow[t]{2}{*}{ PRES0 } & -0.054 & -0.106 & -0.153 \\
\hline & $(0.037)$ & $(0.075)$ & $(0.082)$ \\
\hline \multirow[t]{2}{*}{ NEWYR1 } & 0.017 & 0.037 & 0.036 \\
\hline & $(0.020)$ & $(0.040)$ & $(0.044)$ \\
\hline \multirow[t]{2}{*}{ YROFF1 } & 0.040 & 0.011 & 0.036 \\
\hline & $(0.032)$ & $(0.064)$ & $(0.070)$ \\
\hline \multirow[t]{2}{*}{ NEWYR2 } & $0.042 * *$ & $0.066^{*}$ & $0.090 * *$ \\
\hline & $(0.016)$ & $(0.032)$ & $(0.035)$ \\
\hline \multirow[t]{2}{*}{ YROFF2 } & 0.050 & 0.014 & 0.017 \\
\hline & $(0.030)$ & $(0.060)$ & $(0.066)$ \\
\hline \multirow[t]{2}{*}{ NEWYR3 } & $0.032^{*}$ & 0.053 & $0.076^{*}$ \\
\hline & $(0.015)$ & $(0.030)$ & $(0.033)$ \\
\hline \multirow[t]{2}{*}{ YROFF3 } & $0.067 *$ & 0.041 & 0.063 \\
\hline & $(0.028)$ & $(0.056)$ & $(0.061)$ \\
\hline \multirow[t]{2}{*}{ LENDT } & $-0.169 * *$ & $-0.699 * *$ & $-0.200 * *$ \\
\hline & $(0.015)$ & $(0.073)$ & $(0.061)$ \\
\hline \multirow[t]{2}{*}{ TOTINC } & $1.180 * *$ & $1.909 * *$ & $1.545 * *$ \\
\hline & $(0.264)$ & $(0.533)$ & $(0.585)$ \\
\hline \multirow[t]{2}{*}{ POP } & $0.316^{*}$ & 0.342 & -0.205 \\
\hline & $(0.161)$ & $(0.313)$ & $(0.342)$ \\
\hline \multirow[t]{2}{*}{ PCINC } & $0.662 * *$ & $1.253^{* *}$ & $0.834^{*}$ \\
\hline & $(0.167)$ & $(0.338)$ & $(0.368)$ \\
\hline \multirow[t]{2}{*}{ TOTERN } & $-1.050 * *$ & $-1.568 * *$ & $-1.715^{* *}$ \\
\hline & $(0.258)$ & $(0.518)$ & $(0.565)$ \\
\hline \multirow[t]{2}{*}{ TOTEMP } & 0.036 & 0.0409 & 0.040 \\
\hline & $(0.021)$ & $(0.042)$ & $(0.046)$ \\
\hline \multirow[t]{2}{*}{ PJEARN } & -0.752 & -0.931 & 0.354 \\
\hline & (1.304) & $(2.632)$ & $(0.287)$ \\
\hline \multirow[t]{2}{*}{ DTOTINC3 } & 0.567 & 0.347 & 0.656 \\
\hline & $(0.437)$ & $(0.883)$ & $(0.967)$ \\
\hline \multirow[t]{2}{*}{ DPOP3 } & -0.215 & -0.551 & -0.560 \\
\hline & $(0.191)$ & $(0.387)$ & $(0.426)$ \\
\hline \multirow[t]{2}{*}{ DPCINC3 } & $0.714 * *$ & $0.858^{*}$ & $0.951^{*}$ \\
\hline & $(0.182)$ & $(0.369)$ & $(0.403)$ \\
\hline \multirow[t]{2}{*}{ DTOTERN3 } & $-0.739^{*}$ & -0.566 & -0.685 \\
\hline & $(0.360)$ & $(0.727)$ & $(0.793)$ \\
\hline \multirow{2}{*}{ DTOTEMP3 } & $0.054 *$ & 0.074 & $0.091 *$ \\
\hline & $(0.021)$ & $(0.043)$ & $(0.047)$ \\
\hline \multirow[t]{2}{*}{ DPJEARN3 } & 0.435 & 0.432 & 1.943 \\
\hline & (1.049) & $(2.117)$ & $(2.311)$ \\
\hline County fixed effects & Yes & Yes & Yes \\
\hline Year fixed effects & Yes & Yes & Yes \\
\hline R-Squared & 0.546 & 0.435 & 0.430 \\
\hline
\end{tabular}

NOTE: $* *$ and $*$ indicate statistical significance at $1 \%$ and $5 \%$ respectively. LENDT represents initial year county total lending, CRA lending, and minority lending for the three regressions, respectively. 
Table 7. Government-backed Mortgage Lending Regression Results

The dependent variables are the percentage change in total government-backed, CRA government-backed, and minority government-backed lending in a county over 3 years.

\begin{tabular}{|c|c|c|c|}
\hline \multirow{3}{*}{ AGR0 } & Total Lending & CRA Lending & Minority Lending \\
\hline & -0.007 & -0.028 & -0.039 \\
\hline & $(0.047)$ & $(0.072)$ & $(0.098)$ \\
\hline \multirow[t]{2}{*}{ PRESO } & 0.067 & 0.126 & -0.024 \\
\hline & $(0.064)$ & $(0.098)$ & $(0.133)$ \\
\hline \multirow[t]{2}{*}{ NEWYR1 } & 0.008 & 0.033 & -0.015 \\
\hline & $(0.034)$ & $(0.052)$ & $(0.071)$ \\
\hline \multirow[t]{2}{*}{ YROFF1 } & 0.006 & 0.020 & -0.005 \\
\hline & $(0.054)$ & $(0.084)$ & $(0.114)$ \\
\hline \multirow[t]{2}{*}{ NEWYR2 } & -0.021 & -0.034 & -0.032 \\
\hline & $(0.027)$ & $(0.042)$ & $(0.056)$ \\
\hline \multirow{2}{*}{ YROFF2 } & 0.017 & -0.020 & 0.055 \\
\hline & $(0.051)$ & $(0.079)$ & $(0.107)$ \\
\hline \multirow[t]{2}{*}{ NEWYR3 } & 0.015 & -0.010 & -0.020 \\
\hline & $(0.025)$ & $(0.039)$ & $(0.053)$ \\
\hline \multirow[t]{2}{*}{ YROFF3 } & -0.012 & -0.043 & 0.097 \\
\hline & $(0.047)$ & $(0.073)$ & (0.099) \\
\hline \multirow[t]{2}{*}{ LENDT } & $-0.366^{* *}$ & $-0.707 * *$ & $-0.559 * *$ \\
\hline & $(0.048)$ & $(0.124)$ & $(0.166)$ \\
\hline \multirow[t]{2}{*}{ TOTINC } & -0.218 & -0.288 & -0.161 \\
\hline & $(0.452)$ & (0.699) & $(0.953)$ \\
\hline \multirow[t]{2}{*}{ POP } & 0.308 & 0.252 & 0.475 \\
\hline & $(0.262)$ & $(0.405)$ & $(0.550)$ \\
\hline \multirow[t]{2}{*}{ PCINC } & 0.197 & 0.136 & 0.293 \\
\hline & $(0.287)$ & $(0.445)$ & $(0.605)$ \\
\hline \multirow[t]{2}{*}{ TOTERN } & 0.275 & 0.161 & -0.009 \\
\hline & $(0.439)$ & $(0.679)$ & $(0.920)$ \\
\hline \multirow[t]{2}{*}{ TOTEMP } & 0.031 & 0.051 & 0.035 \\
\hline & $(0.035)$ & $(0.055)$ & $(0.075)$ \\
\hline \multirow[t]{2}{*}{ PJEARN } & -0.339 & -0.365 & -0.131 \\
\hline & $(0.223)$ & $(0.345)$ & $(0.468)$ \\
\hline \multirow[t]{2}{*}{ DTOTINC3 } & -0.171 & 1.472 & -0.246 \\
\hline & $(0.747)$ & $(1.157)$ & (1.574) \\
\hline \multirow[t]{2}{*}{ DPOP3 } & $1.097 * *$ & 0.686 & 1.358 \\
\hline & $(0.356)$ & $(0.547)$ & $(0.797)$ \\
\hline \multirow[t]{2}{*}{ DPCINC3 } & -0.051 & $-1.134 *$ & -0.258 \\
\hline & $(0.310)$ & $(0.480)$ & $(0.652)$ \\
\hline \multirow[t]{2}{*}{ DTOTERN3 } & -0.584 & -1.647 & -0.294 \\
\hline & $(0.615)$ & $(0.952)$ & $(1.291)$ \\
\hline \multirow[t]{2}{*}{ DTOTEMP3 } & 0.015 & 0.031 & 0.027 \\
\hline & $(0.036)$ & $(0.056)$ & $(0.076)$ \\
\hline \multirow[t]{2}{*}{ DPJEARN3 } & 0.278 & 0.244 & 0.165 \\
\hline & $(0.179)$ & $(0.277)$ & $(0.376)$ \\
\hline County fixed effects & Yes & Yes & Yes \\
\hline Year fixed effects & Yes & Yes & Yes \\
\hline R-Squared & 0.469 & 0.442 & 0.358 \\
\hline
\end{tabular}

NOTE: $* *$ and $*$ indicate statistical significance at $1 \%$ and 5\% respectively. LENDT represents initial year county total lending, CRA lending, and minority lending for the three regressions, respectively. 


\section{NOTES}

${ }^{1}$ Low- and moderate-income is collectively referred to as "lower-income" throughout this paper.

${ }^{2}$ In a very small number of cases, agreements have involved a city governmental entity.

${ }^{3}$ One exception to this is if the lender responds to the agreement by subsidizing uncreditworthy borrowers, perhaps by using proceeds from other lines of business.

${ }^{4}$ Conceivably, a CRA agreement could result in a reduction in the amount of lending in a market. This could occur if a lender involved in the agreement expends additional resources to attract loans and thus faces increased costs associated with loan origination. In such a situation, the lender will have to impose a higher creditworthiness standard in equilibrium. However, in a perfectly competitive environment, if the lender were truly a price taker, this effect would be minimal at best.

${ }^{5}$ A reviewer noted that it may be possible for lenders to acquire improved information at less cost than that required by CRA agreements. While this may be true, it is important to recall that the rationing outcome is an equilibrium notion. That is, no incentives exist that will lead a rational lender to take steps to increase the amount of information they have available. In this context, a CRA agreement can be a mechanism for inducing "out-of-equilibrium" behavior that can lead to a new and preferred equilibrium.

${ }^{6}$ Similar mechanisms can be detailed for the other potential causes of rationing. For example, agreements could force a lender with market power to extend more than their profit-maximizing quantity of loans. Although not optimal for the lender, such an outcome would be socially beneficial, as it would increase total surplus.

${ }^{7}$ The data on this are mixed. All the agreements in our data have expiration dates, although many are effectively renewed upon expiration. In addition, the more recent agreements in our data have longer periods of activity than the earlier agreements.

${ }^{8}$ NCRC publishes its list in CRA Commitments, which also reviews innovative provisions of CRA agreements in the areas of home mortgage, small business, and community development lending and other CRA-related investments. More information on NCRC can be obtained via their website at http://www.ncrc.org or by phone at 202-628-8866.

${ }^{9} \mathrm{We}$ view national pledges to be too distributed to have a significant impact on a specific county.

${ }^{10}$ Thus, problems that could potentially arise from changes in the geographic boundaries of an MSA are avoided.

${ }^{11}$ We replicated the analysis using a panel from 1994 to 1999 to explore whether the use of lagged variables influenced results. Lagged variables could account for some delays that might occur between agreement initiation and actions. Because lagged variables generally did not show significant relationships with changes in lending and did not affect other coefficient estimates, estimates using these specifications are not shown.

${ }^{12}$ See Avery, Bostic, Calem and Canner (1999).

${ }^{13}$ An extensive literature in urban growth has demonstrated the importance of initial conditions for subsequent patterns of growth. See, for example, Bostic, Gans and Stern (1997).

${ }^{14}$ By contrast, it is conceivable that construction of homes could precede growth along these dimensions.

${ }^{15}$ One reviewer noted that variation in house price movements, which is not in our specification, may play an important role in variation in demand for mortgages. While the fixed effects approach accounts for this indirectly, we also considered a direct assessment of how the inclusion of changes in house prices affects the results. We were able to obtain data on house price movements from 1993-1997 for each county in the panel using county, MSA, and state median house prices indices obtained by the Federal Reserve Board. This permitted the explicit inclusion of house price movements for half of the sample (initial years 1993 and 1994). The results obtained from re-estimating this augmented model on the shortened panel mirror those obtained using the baseline specification and the full panel.

${ }^{16}$ An agreement was considered to be in effect in a given year if (1) it had been initiated prior to July 1 of the year in question and had not expired as of December 31, or (2) it was active as of January first of the given year and had not expired as of June 30.

${ }^{17}$ See Board of Governors of the Federal Reserve System (2000). 